\title{
Çocukluk Çağı Beyin Sapı Tümörleri
}

\author{
Brainstem Tumor in Children
}

\author{
DBuket Kara', @ Güler Yavaş², @Yavuz Köksal' \\ 'Selçuk Üniversitesi, Tıp Fakültesi, Çocuk Hematoloji ve Onkoloji Anabilim Dalı, Konya, Türkiye \\ ${ }^{2}$ Başkent Üniversitesi, Tıp Fakültesi, Radyasyon Onkolojisi Anabilim Dalı, Ankara
}

\section{ÖZ}

Amaç: Bu çalışmanın amacı, beyin sapı tümör tanısı alan ve tedavi edilen hastalarımızın klinik bulguları, tedavi yaklaşımları ve sonuçlarını değerlendirmektir.

Gereç ve Yöntem: Kliniğimizde, 2006 ile 2019 yılları arasında beyin sapı tümörü tanısı alan ve tedavi alan hastaların onkoloji dosyaları geriye yönelik olarak incelendi.

Bulgular: Beyin sapı tümör tanısı almış 20 hasta çalışmaya dâhil edildi. Hastaların yaşı 2 ile 16 yıl arasında değişiyordu (median, 6,5 yıl). Cinsiyet dağııımı, 14'ü erkek (\%70), 6'sı ise kızdı (\%30). En sık başvuru şikâyetleri, yürüme bozukluğu (\%60), baş ağrısı (\%45) ve gözde kayma (\%40) idi. En sık fizik muayene bulguları ise ataksi (\%55) ve VI. Kranial sinir felci ( \%55) idi. Tümör yerleşimleri, pons (\%90), bulbus (\%5) ve medulla (\%5) idi. Dört hastaya parsiyel kitle eksizyonu yapılabilirken, bir hastada sadece biyopsi yapılabildi. Patolojik incelemede tanılar, grade II astrositom (n: 2), pilositik astrositom (n:1), primitif nöroektodermal tümör (n: 1 ) ve glioblastoma (n: 1$)$ idi. En sık uygulanan tedavi yaklaşımı radyoterapi + kemoterapi (n: 7, \%35) idi. İzlem süreleri 1 ay ile 11 yıl arasında değişiyordu (median, 10,5 ay). Genel yaşam oranı \%19,5 idi.

Sonuç: Çocukluk çağının birçok kanserinde ve hatta beyin tümörlerinde multidisipliner yaklaşımlarla yaşam oranlarında artışlar olmasına karşın, özellikle diffüz intrensek pons gliomlarında maalesef istenilen başarı elde edilememiştir. Özellikle kemoterapide yeni tedavi yaklaşımlara ihtiyaç vardır.

Anahtar Kelimeler: Beyin sapı tümörleri, çocukluk çağı, radyoterapi, kemoterapi

\section{ABSTRACT}

Objective: The aim of this study is to evaluate the clinical findings, treatment approaches and outcomes of our patients who were diagnosed and treated for brainstem tumor.

Material and Method: Between 2006 and 2019, oncology files of patients diagnosed with brain stem tumor and treated were analyzed retrospectively in our clinic.

Results: Twenty patients with brainstem tumor diagnosis were included in the study. The age of patients ranged from 2 to 16 years (median age, 6.5 years). The gender distribution was 14 males (70\%) and 6 females (30\%). The most common complaints were gait disturbance (60\%), headache $(45 \%)$, and strabismus (40\%). The most common physical examination findings were ataxia (55\%) and 6th cranial nerve palsy (55\%). Tumor locations were pons (90\%), bulbus (5\%) and medulla (5\%). Partial mass excision could be done in four patients, while only one biopsy could be performed in one patient. In the pathological examination, the diagnoses were grade II astrocytoma (n: 2), pilocytic astrocytoma(n: 1) primitive neuroectodermal tumor (n: 1) and glioblastoma ( $n: 1)$. The most common treatment approach was radiotherapy + chemotherapy (n: 7, 35\%). Follow-up time varied between 1 month and 11 years (median, 10.5 months). The overall survival rate was $19.5 \%$.

Conclusion: Despite the increase in overall survival rates with multidisciplinary approaches in many cancers and even brain tumors of childhood, unfortunately the desired success could not be achieved especially in diffuse intrinsic pons gliomas. New treatment approaches are needed, especially in chemotherapy.

Keywords: Brainstem tumor, children, radiotherapy, chemotherapy 


\section{GíRiş}

Tüm çocukluk çağı santral sinir sistem tümörlerinin yaklaşı \% 10 ile \%20'sini oluşturan beyin sapı tümörlerinin \%90'ı glial hücre kaynaklıdır. Hastaların çok önemli bir kısmı 10 yaşın altındadır $(1,2)$. Bu güne kadar, beyin sapı glial tümörlerin çeşitli sınıflandırılmalar kullanılmış olmasına karşın günümüzde sıklıkla: (i) diffüz intrensek pons gliomları, (ii) intrensek fokal tümörler, (iii) ekzofitik tümörler ve (iv) serviko medüller bileşke tümörleri olarak 4 başık altında sınıflandırma kullanılmaktadır (13). Genellikle başvuru semptomları ataksi, piramidal yol bulguları ya da kranial sinir felçleridir (3).

Çocukluk çağının birçok kanserinde ve hatta beyin tümörlerinde multidisipliner yaklaşımlarla yaşam oranlarında artışlar olmasına karşın, özellikle diffüz intrensek pons gliomlarında maalesef istenilen başarı elde edilememiştir. Ancak, son yıllarda cerrahinin uygulanabilmesiyle beraber radyoterapi ile özellikle fokal beyin sapı tümörleri ile medulla tümörlerinde yaşar oranları artmıştır.

Bu çalışmanın amacı, beyin sapı tümör tanısı alan ve tedavi edilen hastalarımızın klinik bulguları ile tedavi yaklaşımlarını değerlendirmektir.

\section{GEREÇ VE YÖNTEM}

Kliniğimizde, 2006 ile 2019 yılları arasında beyin sapı tümör tanısı alan hastaların dosyaları geriye yönelik olarak incelendi. Hastaların dosyalarından, yaş, cinsiyet, başvuru şikâyeti, fizik muayene bulguları, tedavi yaklaşımları, hastaların izlem sonuçları ve izlem süreleri kaydedildi.

Devamlı değişkenler ortalama \pm standart sapma ile gösterilirken kategorik veriler ise $\mathrm{n}(\%)$ olarak verildi. Kategorik verilerde frekans ve yüzde rakamları verildi. Hastaların genel yaşam analizleri için Kaplan Meier yöntemi kullanıldı.

Çalışma için 17.06.2020 tarihinde Selçuk Üniversitesi Tıp Fakültesi Etik Kurulu'ndan 2020/11 karar numarası ile etik kurul onamı alındı.

\section{BULGULAR}

2006 ile 2019 yılları arasında kliniğimizde beyin sapı tümör tanısı almış 20 hasta çalışmaya dâhil edildi. Hastaların yaşı 2 ile 16 yıl arasında değişiyordu (median, 6,5 yı). Hasta yaşlarının mod değeri ise 6 yıl idi. Hastaların 14 'ü erkek (\%70), 6'sı ise kızdı (\%30).

Hastaların klinik bulguları Tablo 1'de özetlenmiştir. Semptom süresi 15 gün ile 2 ay arasında değişitordu (median, 1 ay). Hastaların en sık başvuru şikâyetleri, yürüme bozukluğu (n: 12, \%60), baş ağrısı ( $\mathrm{n}: 9, \% 45)$ ve gözde kayma ( $\mathrm{n}: 8, \% 40)$ idi. En sık fizik muayene bulguları ise ataksi (n: 11,\%55) ve VI. kranial sinir felci (n: 11,\%55) idi.
Tablo 1. Beyin Sapı Glial Tümörlü Hastaların Şikâyet ve Fizik Muayene Bulguları

\begin{tabular}{lcc}
\hline SEMPTOM & $\mathbf{n}$ & \% \\
\hline Yürüme bozukluğu & 12 & 60 \\
Baş ağrısı & 9 & 45 \\
Gözde kayma & 8 & 40 \\
Konuşma bozukluğu & 4 & 20 \\
Baş dönmesi & 3 & 15 \\
Bulantı & 2 & 10 \\
Çift görme & 2 & 10 \\
Kusma & 2 & 10 \\
Gelişme geriliği & 1 & 5 \\
Yutma güçlüğü & 1 & 5 \\
BULGU & $\mathrm{n}$ & $\%$ \\
Ataksi & 11 & 55 \\
VI. Kranial sinir felci & 11 & 55 \\
VII. Kranial sinir felci & 3 & 15 \\
Hemiparezi & 1 & 5 \\
III. Kranial sinir felci & 1 & 5 \\
\hline
\end{tabular}

On sekiz hastada tümör yerleşim yeri pons (\%90) iken, birer hastada bulbus ve medulla oblangatada idi.

Tümöre yönelik cerrahi girişim 5 hastada uygulandı. Cerrahi girişimlerden 4'ü parsiyel kitle eksizyonu iken, bir hastada sadece biyopsi yapılabildi. Bir hastaya hidrosefali komplikasyonuna yönelik ventriküloperitoneal şant uygulandı. Patolojik incelemede tanılar, grade II astrositom ( $\mathrm{n}: 2$ ), pilositik astrositom (n: 1), primitif nöroektodermal tümör (n: 1) ve glioblastoma ( $\mathrm{n}: 1)$ idi.

Hastalara uygulanan tedavi yaklaşımları Tablo 2'de özetlenmiştir. En sık uygulanan tedavi yaklaşımı radyoterapi + kemoterapi (n: 7, \%35) idi.

\begin{tabular}{lcc}
\hline Tablo 2. Tedavi Yaklaşımları & & \\
\hline Tedavi yaklaşımı & n & $\%$ \\
\hline Radyoterapi + kemoterapi & 7 & 35 \\
Radyoterapi & 5 & 25 \\
Cerrahi + radyoterapi + kemoterapi & 4 & 20 \\
Cerrahi + kemoterapi & 1 & 5 \\
Herhangi bir tedaviyi kabul etmeyen & 3 & 15 \\
\hline
\end{tabular}

Tablo 3. Kemoterapi Protokolleri

\begin{tabular}{lll} 
& $\mathbf{n}$ & $\%$ \\
\hline Sisplatin + etoposid & 6 & 30 \\
Nimotuzumab & 4 & 20 \\
Karboplatin + vinkristin & 2 & 10 \\
Kemoterapi almayan & 8 & 40
\end{tabular}

Yedi hastanın hastalıklı izlemi devamı devam etmektedir (\%35), hastaların izlem süreleri 1 ay ile 11 yıl arasında değişmektedir (median, 10,5 ay). Genel yaşam oranı $\% 19,5$ idi (Resim 1). 


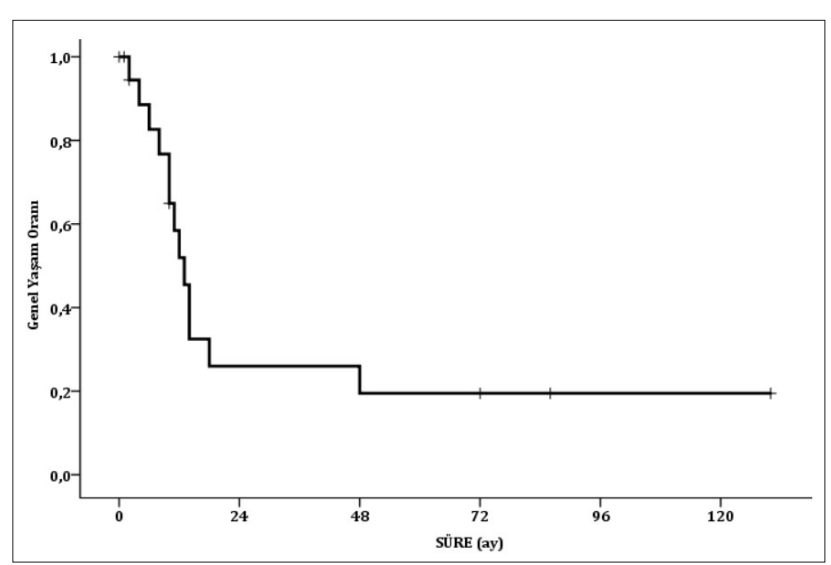

Resim 1. Hastaların genel yaşam oranları

\section{TARTIŞMA}

Beyin sapı tümörleri, çocukluk çağı santral sinir tümörlerinin \%10-20'si, posterior fossa tümörlerinin ise \%25-30'unu oluşturan tümörlerdir. Beyin sapı gliomları çocuklarda yetişkinlerden daha yaygındır. Beyin sapı tümörlerin büyük çoğunluğunu glial hücre kaynaklıdır (1-3). Beyin sapı tümörleri, yaygınlığına göre diffüz ya da fokal ve yerleşim yerine göre sınıflandırılabilir. Beyin sapı tümörleri tedaviye daha az ihtiyaç duyulan düşük dereceli tümörlerden agresif olarak büyüyerek hızla ölüme sebep olan heterojik biyolojik davranışa sahiptir (4). Günümüzde en yaygın kullanılan sınıflandırmada, diffüz intrensek pons gliomları, intrensek fokal tümörler, ekzofitik tümörler ve serviko medüller bileşke tümörleri olarak sınıflandırılır. Pons gliomların çoğu genellikle yüksek dereceli lokal olarak infiltratif olan ve kötü prognoza sahip olan diffuz intrensek pons gliomlarıdır (5). Histolojik olarak bu tümörler genel olarak anaplastik astrositom (Dünya Sağlık Örgütü Sınıflaması - grade 3) veya glioblastomdur (Dünya Sağlık Örgütü Sınıflaması - grade 4). İntrensek fokal tümörler, ekzofitik tümörler ve servikomedüller bileşke tümörleri daha çok lokal büyüme karakteri gösteren, iyi sınırlı, histolojik olarak genelde pilositik astrositom (Dünya Sağlık Örgütü Sınıflaması - grade 1) olarak görülen tümörlerdir (6).

Beyin sapı tümörlerde, demografik özellikleri incelendiğinde, genellikle median yaşın 6-7 yıl olduğu ve cinsiyet dağılımının birbirine yakın olduğu bilinmektedir. Hastalar genelde 10 yaşın altında tanı almaktadırlar (1-3). Bizim çalışmamızda da, median yaşın 6,5 yıl olduğu ve mod değerinin 6 yıl olduğu görülmektedir. Bu özellikleri literatür ile uyumlu, ancak hastalarımızın cinsiyet dağılımına bakıldığında erkek cinsiyetin daha baskın olduğu görülmektedir. Erkek cinsiyet baskınlığının açıklaması tesadüf olabileceği gibi büyük oranda hasta sayımızın az olması ile de açıklamak mümkündür.

Beyin sapı tümörlerde, değişik klinik bulgular gözlenebilse de en çok ataksi, piramidal yol bulguları ya da kranial sinir felçleridir (1, 7-8). Kitlenin boyutuna ve konumuna bağlı olarak semptomlar değişken olmakla beraber özellikle VI. ve VII. Kranial sinir felcine bağlı semptomlar, hemiparezi ve $\% 50$ 'den fazla hastada ataksi bildirilmiştir. Hidrosefali başvuru anında hastaların \%10'undan azında izlenmektedir (9). Şikâyet süresi değişken olmakla beraber genellikle 1-2 aydır. Hastalarımızın en sık başvuru şikâyetleri, yürüme bozukluğu, baş ağrısı ve gözde kaymaydı. İlginç olan bir hastamızda ise gelişme geriliği nedeni ile incelenirken beyin MRG'de tesadüfen bulunmuştu. Fizik muayene bulguları ise, ataksi ve başta VI. kranial sinir felci olmak üzere kraniyal sinir felçleriydi.

Beyin sapı tümörleri içinstandart kullanılangörüntüleme yöntemi MRG'dir. Hastaların semptom ve bulgularına yönelik acil şartlarda Bilgisayarlı Tomografiylede (BT) hastalar tanı almaktadır (10). Hastalarımızın hepsine tanı MRG ile konulmuştur.

Beyin tümörlerinin tedavisinde genel yaklaşım, cerrahi, radyoterapi ve kemoterapidir. Ancak, beyin sapı tümörlerinde cerrahinin yeri oldukça sınırlıdır. Peritümöral ödemin kontrolüne yönelik steroid tedavisi semptomlarınazalmasına belirgin katkıdabulunurancak tedavi edici değildir. Steroidler altta yatan sorunu tedavi etmesede semptomatik tedavi edici ve yaşam kalitesini arttırmaya yönelik hastalara verilmektedir. Uzun yıllar bu hastalar ameliyat edilemez olarak değerlendirilirken son yıllarda, mikrocerrahi tekniklerinde gelişme ve beyin cerrahlarının tecrübesinin artması ile beraber, özellikle fokal beyin sapı tümörlerinde cerrahi yaklaşımlar kullanılabilir hale gelmiştir (2). Hastalarımızın sadece beşine cerrahi girişim uygulanabilmiş ancak sadece dördünde parsiyel eksizyon yapılabilmiştir. Bir hastaya ise tümöre bağlı komplikasyona hidrosefaliye yönelik ventrikuloperitoneal şant ameliyatı yapılmıştır. Diğer hastalarımızda ise maalesef herhangi bir cerrahi girişim yapılamamıştır.

Beyin sapı tümörlerinde, uygulanan tedavi yaklaşımları içinde en çok sadece radyoterapi ya da radyoterapi + kemoterapi uygulaması şeklindedir (7). Radyoterapi, beyin sapı tümörlerinin standart tedavisi içindedir. Radyoterapi pons gliomlarının seyrini değiştiren tek tedavi şeklidir. Doz arttırımı, değiştirilmiş fraksiyonlama yöntemleri ve radyosentisizasyonla yapılan birçok denemeye rağmen bu uygulamaların geleneksel radyoterapiye üstünlüğü kanıtlanamamıştır (11) Eksternal lokal alan şeklinde 54-60 Gy radyoterapi şeklinde uygulanmaktadır. Hiperfraksiyone radyoterapi uygulamaları da kullanılmıştır. Ancak genel yaşam oranları üzerine çok fazla bir katkısı olmamıştır $(12,13)$. Radyoterapinin tümörde yaptığı küçülme dramatik olabilsede yanıt genellikle geçicidir ve median sağkalım yaklaşık 10 aydır ve iki yıllık sağkalım yüzde 10 dan azdır (14). Son yıllarda, eş zamanlı kemoterapi ve radyoterapi tedavi yaklaşımları üzerinde durulmuştur. Tekli kemoterapi ajanları, çoklu kemoterapi rejimleri, 
kök hücre tedavileri denenmiştir (10). Birçok ilaç radyoterapi ile beraber eş zamanlı kullanılmış, ancak bu uygulamada özellikle genel yaşam oranları üzerine ek bir katkı sağlamamıştır (15-20). Hastalarımızda ana tedavi yaklaşımı radyoterapi ya da radyoterpi + kemoterapi şeklindeydi. Radyoterapi, herhangi bir tedaviyi kabul etmeyen 3 hastamız ile tanı anında 3 yaşından küçük bir hastamızda uygulanamadı. Diğer hastalarımızın hepsinde eksternal lokal alan şeklinde radyoterapi uygulandı. Hiçbir hastamızda radyoterapi ile beraber eş zamanlı kemoterapi uygulaması tercih edilmediği görülmektedir.

Kemoterapi uygulamalarında değişik protokoller kullanılmıştır. Önceki yıllarda, ağırlıklı olarak CCNU ya da sisplatin bazlı kemoterapi protokolleri kullanılmıştır. Son zamanlarda ise temozolamid ve nimotuzumab tedavileri ön plana çıkmaktadır. Temozolamid ile ilgili çalışmalarda, Rizzo ve arkadaşları (15) çalışmalarında, radyoterapi ile eş zamanlı temozolamid tedavisi ve ardından adjuvan temozolamid tedavisi uyguladıkları yeni tanı alan diffüz beyin sapı glial tümörlü hastalarının genel yaşam oranları üzerine olumlu bir katkısını görmemişlerdir. Yine benzer şekilde Chassot ve arkadaşlarının (16) ve Jalali ve arkadaşlarının (17) çalışmalarında temozolamidin genel yaşam oranları üzerine olumlu bir etkisi gözlemlememişlerdir. Kebudi ve arkadaşlarının (18) çalışmasında, radyoterapi + temozlamid ya da radyoterapi + kemoterapi alan hastaların genel yaşam oranlarının sadece radyoterapi alan hastalardan daha yüksek olduğu bulunmuştur. Son zamanlarda, beyin sapı glial tümörlerinde nimotuzumab içeren rejimler uygulanabilir ve tolere edilebilir bir tedavi rejimi olarak kullanılmaktadır. Bazı hastaların, nimotuzumab içeren kombinasyonlardan fayda görebileceği gösterilmiştir $(12,13)$. Merkezimizde önceki yıllarda sisplatin temelli kemoterapi tercih edilirken son yıllarda nimotuzumab içeren rejimler kullanılmaktadır.

Birçok tedavi seçenekleri kullanılmış olmasına karşın, özellikle diffüz intrensek pons gliomlarının prognozlarında bir düzelme sağlanamamıştır. Bizim hastalarımız da genel yaşam oranı \%19,5 dir. Uzun süredir yaşayan hastalarımız nörofibromatosis tip 1'li hasta ile nimotuzumab tedavisi kullandığımız bir hastadır.

\section{SONUÇ}

Birçok tedavi yaklaşımları denemiş olmasına karşın, özellikle diffüz intrensek pons gliomlarında istenilen başarı elde edilmemiştir. Tümörün patolojik tanımlanması ve hedefe yönelik tedavilerin geliştirilmesi ile ilgili çalışmalar sürmektedir. Yeni tedavi stratejilerine ihtiyaç vardır.

\section{ETIK BEYANLAR}

Etik Kurul Onayı: Çalışma için 17.06.2020 tarihinde Selçuk Üniversitesi Tıp Fakültesi Etik Kurulu'ndan 2020/11 karar numarası ile etik kurul onamı alındı.

Aydınlatılmış Onam: Çalışma retrospektif olarak dizayn edildiği için hastalardan aydınlatılmış onam alınmamıştır.

Hakem Değerlendirme Süreci: Harici çift kör hakem değerlendirmesi.

Çıkar Çatışması Durumu:Yazarlar bu çalışmada herhangi bir çıkara dayalı ilişki olmadığını beyan etmişlerdir.

Finansal Destek: Yazarlar bu çalışmada finansal destek almadıklarını beyan etmişlerdir.

Yazar Katkıları: Yazarların tümü; makalenin tasarımına, yürütülmesine, analizine katıldığını ve son sürümünü onayladıklarını beyan etmişlerdir.

Teşekkür: Hastalarımızın izlem ve tedavilerinde katkıları bulunan tüm iş ardaşlarımıza teşekkür ederiz.

\section{KAYNAKLAR}

1. Jallo Gl, Biser-Rohrbaugh A, Freed D. Brainstem gliomas. Childs Nerv Syst 2004;20(3):143-53.

2. Başarır $M$, Özek $M$. Beyin sapı tümörlerinde güncel tedavi seçenekleri. Türk Nöroşir Derg 2017;27(1):43-51.

3. Robison NJ, Kieran MW. Diffuse intrinsic pontine glioma:a reassessment. J Neurooncol 2014;119(1):7-15.

4. Monje M, Mitra SS, Freret ME et al. Hedgehog-responsive candidate cell of origin for diffuse intrinsic pontine glioma. Proc Natl Acad Sci U S A 2011;108(11):4453.

5. Fisher PG, Breiter SN, Carson BS, et al. A clinicopathologic reappraisal of brain stem tumor classification. Identification of pilocystic astrocytoma and fibrillary astrocytoma as distinct entities. Cancer 2000;89(7):1569-76.

6. Albright AL. Diffuse brainstem tumors:when is a biopsy necessary? Pediatr Neurosurg 1996;24(5):252-5.

7. El-Khouly FE, Veldhuijzen van Zanten SEM, Santa-Maria Lopez $V$, et al. Diagnostics and treatment of diffuse intrinsic pontine glioma:where do we stand?. J Neurooncol 2019;145(1):177-84.

8. Veldhuijzen van Zanten SEM, Baugh J, Chaney B, et al. Development of the SIOPE DIPG network, registry and imaging repository:a collaborative effort to optimize research into a rare and lethal disease. J Neurooncol 2017;132(2):255-66.

9. Broniscer $A$, Laningham $\mathrm{FH}$, Kocak $\mathrm{M}$, et al. Intratumoral hemorrhage among children with newly diagnosed, diffuse brainstem glioma. Cancer 2006;106(6):1364-71.

10. Epstein F, Constantini S. Practical decisions in the treatment of pediatric brain stem tumors. Pediatr Neurosurg 1996;24(1):24-34.

11. Schild SE, Stafford SL, Brown PD, et al. The results of radiotherapy for brainstem tumors. J Neurooncol 1998;40(2):171-7.

12. Jalali R, Raut N, Arora B, et al. Prospective evaluation of radiotherapy with concurrent and adjuvant temozolomide in children with newly diagnosed diffuse intrinsic pontine glioma. Int J Radiat Oncol Biol Phys 2010;77(1):113-8.

13. Kebudi R, Cakir FB, Agaoglu FY, et al. Pediatric diffuse intrinsic pontine glioma patients from a single center. Childs Nerv Syst 2013;29(4):583-8.

14. Hargrave D, Bartels U, Bouffet E. Diffuse brainstem glioma in children:critical review of clinical trials. Lancet Oncol 2006;7(3):241-8.

15. Kebudi R, Cakir FB. Management of diffuse pontine gliomas in children:recent developments. Paediatr Drugs 2013;15(5):35162.

16. Gallitto $M$, Lazarev $S$, Wasserman I, et al. Role of radiation therapy in the management of diffuse intrinsic pontine glioma:A systematic review. Adv Radiat Oncol 2019;4(3):520-31. 
17. Rizzo D, Scalzone $M$, Ruggiero $A$, et al. Temozolomide in the treatment of newly diagnosed diffuse brainstem glioma in children:a broken promise? J Chemother 2015;27(2):106-10.

18. Chassot A, Canale $S$, Varlet $P$, et al. Radiotherapy with concurrent and adjuvant temozolomide in children with newly diagnosed diffuse intrinsic pontine glioma. J Neurooncol 2012;106(2):399407.

19. Jalali R, Raut N, Arora B, et al. Prospective evaluation of radiotherapy with concurrent and adjuvant temozolomide in children with newly diagnosed diffuse intrinsic pontine glioma. Int J Radiat Oncol Biol Phys 2010;77(1):113-8.

20. Kebudi R, Cakir FB, Agaoglu FY, et al. Pediatric diffuse intrinsic pontine glioma patients from a single center. Childs Nerv Syst 2013;29(4):583-8.

21. Kebudi R, Cakir FB, BaySB, et al. Nimotuzumab-containing regimen for pediatric diffuse intrinsic pontine gliomas:a retrospective multicenter study and review of the literature. Childs Nerv Syst 2019;35(1):83-9.

22. Fleischhack $G$, Massimino $M$, Warmuth-Metz $M$, et al. Nimotuzumab and radiotherapy for treatment of newly diagnosed diffuse intrinsic pontine glioma (DIPG):a phase III clinical study. J Neurooncol. 2019; 143(1):107-13. 